\title{
Nutritional factors and aging in demyelinating diseases
}

\author{
Ana M. Adamo
}

Received: 24 July 2013/Accepted: 7 November 2013/Published online: 6 December 2013

(C) Springer-Verlag Berlin Heidelberg 2013

\begin{abstract}
Demyelination is a pathological process characterized by the loss of myelin around axons. In the central nervous system, oligodendroglial damage and demyelination are common pathological features characterizing white matter and neurodegenerative disorders. Remyelination is a regenerative process by which myelin sheaths are restored to demyelinated axons, resolving functional deficits. This process is often deficient in demyelinating diseases such as multiple sclerosis (MS), and the reasons for the failure of repair mechanisms remain unclear. The characterization of these mechanisms and the factors involved in the proliferation, recruitment, and differentiation of oligodendroglial progenitor cells is key in designing strategies to improve remyelination in demyelinating disorders. First, a very dynamic combination of different molecules such as growth factors, cytokines, chemokines, and different signaling pathways is tightly regulated during the remyelination process. Second, factors unrelated to this pathology, i.e., age and genetic background, may impact disease progression either positively or negatively, and in particular, age-related remyelination failure has been proven to involve oligodendroglial cells aging and their intrinsic capacities among other factors. Third, nutrients may either help or hinder disease progression. Experimental evidence supports the anti-inflammatory role of omega- 6 and omega-3 polyunsaturated fatty acids through the
\end{abstract}

This paper is part of Genes and Nutrition's "Topical Collection on Ageing."

A. M. Adamo $(\square)$

Department of Biological Chemistry, IQUIFIB

(UBA-CONICET), School of Pharmacy and Biochemistry,

University of Buenos Aires, Junín 956,

C1113AAD Buenos Aires, Argentina

e-mail: amadamo@qb.ffyb.uba.ar competitive inhibition of arachidonic acid, whose metabolites participate in inflammation, and the reduction in $\mathrm{T}$ cell proliferation. In turn, vitamin D intake and synthesis have been associated with lower MS incidence levels, while vitamin D-gene interactions might be involved in the pathogenesis of MS. Finally, dietary polyphenols have been reported to mitigate demyelination by modulating the immune response.

Keywords Demyelination - Remyelination . Nutritional Factors

$\begin{array}{ll}\text { Abbreviations } \\ \text { OLs } & \text { Oligodendroglial cells } \\ \text { CNS } & \text { Central nervous system } \\ \text { MS } & \text { Multiple sclerosis } \\ \text { EAE } & \text { Experimental autoimmune encephalomyelitis } \\ \text { CPZ } & \text { Cuprizone } \\ \text { OPCs } & \text { Oligodendroglial progenitor cells } \\ \text { PDGFR } \alpha & \text { Platelet-derived growth factor receptor } \alpha \\ \text { GFAP } & \text { Glial fibrillary acidic protein } \\ \text { SVZ } & \text { Subventricular zone } \\ \text { PLP } & \text { Proteolipid protein } \\ \text { MBP } & \text { Myelin basic protein } \\ \text { CNPase } & 2^{\prime}, 3^{\prime} \text {-Cyclic nucleotide } 3^{\prime} \text {-phosphodiesterase } \\ \text { TNF } \alpha & \text { Tumor necrosis factor- } \alpha \\ \text { IL } & \text { Interleukin } \\ \text { NPCs } & \text { Neural precursor cells } \\ \text { EGFR } & \text { Epidermal growth factor receptor } \\ \text { LINGO-1 } & \text { Leucine-rich repeat- and Ig domain-containing } \\ & \text { NOGO receptor-interacting protein 1 } \\ \text { Shh } & \text { Sonic hedgehog } \\ \text { Hes } & \text { Hairy/enhancer of split } \\ \text { aTf } & \text { Apotransferrin } \\ \text { IGF-1 } & \text { Insulin growth factor-1 } \\ & \end{array}$


PUFAs Polyunsaturated fatty acids

TGF- $\beta \quad$ Tumor growth factor- $\beta$

PPAR Peroxisome proliferator-activated receptors

25(OH)D 25-Hydroxyvitamin D

\section{Introduction}

Myelin biology dates back to 1,717 , when Leeuwenhoek established the existence of nervules surrounded by fatty parts (Rosenbluth 1999). Two and a half centuries later, such fatty parts were shown to belong to a highly specialized membrane, i.e., myelin, generated by mature oligodendroglial cells (OLs) in the central nervous system (CNS) and by Schwann cells in the peripheral nervous system. Myelin is a very special membrane, with unique molecular composition and architecture. One of its main functions is to isolate axons and cluster sodium channels at Ranvier nodes, thus allowing for saltatory transmission of action potential between nodes (Waxman 2006). Myelin development and saltatory nerve conduction constitute the basis for fast information processing in a relatively small space.

Demyelination is a pathological process consisting in the loss of myelin sheaths around axons. In the CNS, demyelination is usually a consequence of OL damage and is referred to as primary demyelination, as opposed to that occurring as a consequence of primary axonal loss, regarded as secondary demyelination or Wallerian degeneration (Franklin and Ffrench-Constant 2008).

\section{Demyelinating diseases}

From a clinical standpoint, white matter disorders involving myelin affect approximately a million people around the world and include a wide range of pathologies. Two key causes of primary demyelination are the following: (1) genetic abnormalities affecting OLs (leukodystrophies) and (2) inflammatory damage affecting myelin and OLs.

Genetic abnormalities affecting glia comprise inherited lysosomal storage diseases, including metachromatic leukodystrophy and Krabbe disease; peroxisomal disorders, including X-linked adrenoleukodystrophy; and deficiency or misfolding of select myelin proteins, including Pelizaeus-Merzbacher disease, among others. Multiple sclerosis (MS) is the most prominent among inflammatory demyelinating diseases and, unlike leukodystrophies, is characterized by the presence of focal neurological lesions. It is, however, a complex disease whose clinical features vary among patients.
Multiple sclerosis clinical progression is variable, generally beginning with reversible episodes of neurological disability between the third and fourth decades of life and progressing to continuous and irreversible neurological disability between the sixth and seventh decades (Trapp and Nave 2008). MS symptoms are the result of myelinated tract interruption in the CNS. Several lines of mice carrying myelin protein null mutations provided the proof that axonal degeneration is a consequence of chronic demyelination (Trapp and Nave 2008). In this context, remyelination is defined as the process through which myelin sheaths are restored to demyelinated axons, which is associated with functional recovery (Franklin 2002). Remyelination is the response to demyelination and is necessary for axon survival. Thus, it should be considered as a regenerative process, similar to other regenerative processes taking place in other tissues. In toxic-based models of demyelination, as opposed to experimental autoimmune encephalomyelitis (EAE) or virus-induced demyelination, full remyelination takes place spontaneously, which allows for a thorough study of the mechanisms involved in demyelination/remyelination processes.

Demyelination is undoubtedly part of MS pathology; however, in recent years, neuronal loss and axonal loss have been proven to be a consequence of chronic demyelination and the main driving force for neurodegeneration (Trapp and Nave 2008) in demyelinating disorders.

\section{Underlying mechanisms in demyelination/ remyelination processes}

Animal models widely used to study demyelination processes include (1) EAE, (2) virus-induced models such as Theiler's murine encephalomyelitis virus, and (3) toxininduced models, such as cuprizone (CPZ) administration and focal demyelination through lysolecithin injection. These experimental models have provided a vast amount of information on remyelination. Findings in this field have established that (1) the number of oligodendrocytes present in a remyelinated area is larger than the number of these cells present in the area previous to demyelination, which indicates that new oligodendrocytes are generated (Prayoonwiwat and Rodriguez 1993), and (2) post-mitotic oligodendrocytes that survive the lesion produced by the demyelinating agent do not contribute to remyelination (Keirstead and Blakemore 1997). The question raised from these findings refers to the origin of these new oligodendrocytes. There is a consensus in the hypothesis that most of them, probably all of them, derive from oligodendroglial progenitor cells (OPCs) widely spread throughout the CNS (Wood and Bunge 1991; Blakemore and Keirstead 1999), which are usually identified through the expression of 
proteoglycan NG2 or platelet-derived growth factor receptor- $\alpha$ mRNA (Wilson et al. 2006). In addition, remyelination can be mediated by periventricular cells, such as progenitors derived from the rostral migratory stream or from glial fibrillary acidic protein-positive B-type stem cells present in the adult subventricular zone (SVZ) (Menn et al. 2006). It is worth pointing out that these alternative sources of OPCs only contribute to remyelinating areas that are anatomically close to the SVZ, and, even in these cases, their relative contribution is uncertain. For remyelination to actually take place, it is necessary to populate the demyelinated area with enough OPCs, either those resident in the area or those that can be recruited from neighboring white matter (Carroll and Jennings 1994). Recruitment involves both the proliferation and migration of OPCs, which, once in the area, have to differentiate to mature OLs with myelinating capacity in order to complete remyelination.

The toxin-induced models mentioned above have proven NG2-positive cell recruitment from the SVZ to the demyelinated area. These cells differentiate and become mature OLs sequentially expressing myelin proteins such as proteolipid protein (PLP), myelin basic protein (MBP), and $2^{\prime}, 3^{\prime}$-cyclic nucleotide $3^{\prime}$-phosphodiesterase. These findings prove that remyelination mechanisms are tightly regulated and involve a wide range of molecules, including cytokines (Mason et al. 2001) and chemokines (Patel et al. 2010), transcription factors (Qi et al. 2001), growth factors (Aguirre et al. 2007; Murtie et al. 2005), micro-RNA (Junker et al. 2009), and different signaling pathways (John et al. 2002).

Cytokines mediate the inflammatory response that promotes pathogen removal and thus prevents excessive tissue damage. However, excessive cytokine production may lead to exacerbated inflammation and consequent cell death. In the CNS, in particular, certain cytokines play a key role in regenerative processes. Tumor necrosis factor- $\alpha$ (TNF $\alpha)$, through $\mathrm{TNF} \alpha$ receptors $\mathrm{R} 1$ and $\mathrm{R} 2$, activates cell death, on the one hand, and NFKB-mediated survival, on the other. MS patients tend to have higher levels of TNFa, both in cerebrospinal fluid and in serum, than control patients. In turn, these values correlate with disease severity (Beck et al. 1988; Maimone et al. 1991). Interleukin (IL)-1 $\beta$ is another pro-inflammatory cytokine related to the physiopathology of demyelinating diseases such as MS and, similarly to $\mathrm{TNF} \alpha$, is associated with the worsening of CNS pathology (de Jong et al. 2002).

Chemokines induce chemotaxis, which is necessary to attract cells to take part in the immune response at the infected or injured site. Certain chemokines, such as CXCL12 and CXCL1, are induced during CNS development and coordinate the proliferation, migration, and differentiation of neural precursor cells (NPCs) (Stumm et al. 2007; Tsai et al. 2002), which suggests they might also participate in CNS regenerative processes. In this way, Patel et al. (2010) demonstrated that CXCR4 (the receptor of CXCL12) activation is important for the remyelination of the CPZ-demyelinated mouse by induction of OPC differentiation.

Growth factors are biologically active polypeptides controlling target cell growth and differentiation and are important during the remyelination process. Thus, it was demonstrated that epidermal growth factor receptor signaling is involved in both the repopulation by OPCs and the remyelination of lysolecithin-induced corpus callosum demyelination (Aguirre et al. 2007).

Signaling pathways possibly involved in the remyelination process include those mediated by leucine-rich repeat- and Ig domain-containing NOGO receptor-interacting protein 1 (LINGO-1), Wnt, Sonic hedgehog (Shh), and Notch1. LINGO-1 has been identified as a negative regulator of $\mathrm{OL}$ differentiation ( $\mathrm{Mi}$ et al. 2005). The treatment of OPC cultures with anti-LINGO-1shRNA has been reported to generate an increase in cell morphological differentiation. On the other hand, LINGO-1-deficient mice or mice treated with an anti-LINGO-1 antibody exhibited greater remyelination and functional recovery when submitted to EAE (Mi et al. 2007). The same observations were made when animals were submitted to toxin-induced demyelination (Mi et al. 2009). As for the Wnt signaling pathway, Fancy et al. (2009) identified pathway-associated genes that are induced during remyelination in mice submitted to experimental demyelination. During remyelination, Tcf4-mediated activation of Wnt negatively regulates OPC differentiation (Fancy et al. 2009; Ye et al. 2009).

During CNS development, the secretion protein Shh is necessary for the commitment of the first wave of OPCs arising from the ventral region of the spinal cord and forebrain (Fuccillo et al. 2006). In the adult brain, Shh delivery induces an increase in the population of OPCs in the cerebral cortex and corpus callosum (Loulier et al. 2006). Recent studies using lysolecithin-induced corpus callosum demyelination showed that the Shh signaling is activated during remyelination and that adenovirus-mediated Shh delivery stimulates OPC proliferation and maturation (Ferent et al. 2013).

The Notch signaling pathway has been implicated in the selection process of neural progenitors present in the neural tube of vertebrates (Lewis 1996). Notch is a type I transmembrane receptor which responds to the binding of specific ligands and consequently undergoes a sequence of two proteolytic cleavages. The $\gamma$-secretase complex releases the Notch intracellular domain (NICD), which translocates to the nucleus and activates the transcription of Notch target genes (Kopan and Ilagan 2009), such as the bHLH-type transcriptional repressors known as hairy/enhancer of split (Hes) genes. Upon binding to canonical Delta, Serrate/ 
Jagged, and Lag-2 ligands, Notch activation maintains the pool of NPCs in their undifferentiated state and allows for the generation of OPCs (Artavanis-Tsakonas et al. 1999), thus blocking OL maturation through these ligands (Wang et al. 1998). In addition, NB-3 and F3/contactin, two neural cell adhesion molecules, act as non-canonical Notch ligands participating in OL generation (Cui et al. 2004; Hu et al. 2003). NB-3 triggers NICD nuclear translocation, promoting oligodendrogenesis from progenitor cells and OPC maturation via Deltex1 (Cui et al. 2004). We found that the treatment of demyelinated rats with a single apotransferrin (aTf) (350 ng) injection at the time of CPZ withdrawal induces a marked increase in myelin deposition as compared to the spontaneous remyelination observed in control animals (Adamo et al. 2006). Accordingly, different authors have reported the relevant role of aTf during myelination increasing brain myelin content, including proteins and their mRNAs (Escobar Cabrera et al. 1997, 1994, 2000), regulating MBP gene transcription (Espinosa de los Monteros et al. 1989, 1999), synergizing with insulin growth factor-1 (IGF-1), and enhancing myelination in myelin-deficient rats (Espinosa-Jeffrey et al. 2002). We recently observed that both canonical and non-canonical Notch signaling pathways are involved in demyelination/ remyelination. Notch activation was observed to trigger Hes5 expression as a consequence of lysolecithin-induced focal demyelination of corpus callosum, which might promote OPC proliferation. During aTf-induced remyelination, the expression of F3/contactin appeared to mediate Notch activation and thus induce aTf-mediated OL maturation (Aparicio et al. 2013).

In summary, remyelination occurring after demyelinating injuries is a very complex process involving different cellular populations, regulated by several molecules (e.g., growth factors, cytokines) and involving multiple signaling cascades (e.g., Notch signaling, Shh signaling). Knowledge of these events has significantly advanced in the last decades. However, many aspects remain unknown, and remyelinating therapeutic approaches remain limited and constitute a challenging field of research.

\section{Remyelination and aging}

Remyelination occurs efficiently in some situations and fails in others. This irregularity in remyelination has been studied using toxin-induced demyelination models. In this context, age was demonstrated to be one of the most important factors influencing CNS remyelination after a demyelinating event. In particular, the rate of remyelination is what changes in the aging CNS rather than its extent (Shields et al. 1999). The decrease in CNS remyelination rates occurring as a consequence of aging is a major complication for remyelinating therapies, in particular for long-lasting demyelinating disorders such as MS. It is also important to consider the age-related modifications of the innate immune and growth factor responses to the demyelination process which interfere with myelin repair (Hinks and Franklin 2000; Zhao et al. 2006). Studies of OPC response during remyelination of toxin-induced demyelination in the caudal cerebellar peduncle from young and old adult rats indicate that the inefficiency of remyelination associated with aging is due to the impairment of OPC recruitment and the subsequent failure of OPCs in differentiating into myelinating OL (Sim et al. 2002). In this regard, it was demonstrated that the epigenetic control of gene expression related to aging regulates remyelination. Therefore, in young animals, remyelination occurs as a consequence of the downregulation of inhibitors of OPC differentiation, concomitantly with the recruitment of histone deacetylases to promoter regions. In old animals, this recruitment is inefficient and thus hinders efficient remyelination due to a decrease in the ability of OPCs to differentiate into mature OLs with myelinating capacity (Shen et al. 2008). Using heterochronic parabiosis (Villeda et al. 2011) in a toxin-induced focal demyelination model of mouse spinal cord, Ruckh et al. demonstrated improvements in the remyelination of aged brains mediated by endogenous OPCs whose differentiation capacity was restored by exposing them to a youthful systemic environment. Considering previous hypotheses about the role of the innate immune system in remyelination (Kotter et al. 2006), these results support the idea that young macrophages recruited during remyelination facilitate OPC differentiation by removing inhibitory myelin debris (Ruckh et al. 2012).

Taken together, the above findings give rise to the notion that age-related remyelination failure may implicate not only factors associated with aging OLs and their intrinsic capacities, but also a number of external factors, even outside the CNS, that affect OPC differentiation capacity and ultimately impact myelin repair (Redmond and Chan 2012).

\section{Demyelination/remyelination and nutrients}

MS is the most common CNS-specific demyelinating disorder affecting young adults, and it is a multifactorial disease with unclear etiology. In addition to a genetic predisposition (Ebers and Sadovnick 1994), epidemiological studies suggest a strong association between increased MS prevalence and particular diets (Antonovsky et al. 1965; Cendrowski et al. 1969; Berr et al. 1989; Tola et al. 1994). Studies conducted on dietary factors associated with MS have included fat consumption, particularly saturated 
animal fat (Payne 2001); breastfeeding duration (Isaacs et al. 2010); and the intake of sweets (Antonovsky et al. 1965), alcohol (Berr et al. 1989; Sepcic et al. 1993), smoked meat products (Sepcic et al. 1993), coffee, and tea (Tola et al. 1994). However, Agranoff and Goldberg (1974) implicate foods rich in both omega- 6 and omega- 3 polyunsaturated fatty acids (PUFAs) in negative correlations with MS-omega-3 PUFAs are derived from fish oils, whereas omega-6 PUFAs are obtained from plants such as sunflower, corn, wheat germ, and soybean oils. In particular, it was observed that linoleic (18:2n-6) and arachidonic acids (20:4n-6) are decreased in plasma, platelets, erythrocytes, leukocytes, and cerebrospinal fluid in patients with MS (Baker et al. 1964; Sanders et al. 1968; Gul et al. 1970; Neu 1983). The use of linoleic acid alone or oil containing linoleic acid and $\gamma$-linolenic acid (ratio 7:1) in the treatment for EAE - an induced animal model of CD4 T cellmediated demyelination characterized by inflammationproduced a partial suppression of the incidence and severity of the pathology (Meade et al. 1978). It was further demonstrated that the $\gamma$-linolenic acid had a protective, dose-dependent effect on EAE because of the increase in $\mathrm{T}$ cell tumor growth factor- $\beta$ (TGF- $\beta$ ) transcription and prostaglandin $\mathrm{E}_{2}$ production (Harbige et al. 2000).

Even though the relationship between the dietary intake of fat and the risk of MS is not clear, the anti-inflammatory effects of omega-6 and omega-3 PUFAs are well known. Both omega-6 and omega-3 PUFAs are competitive inhibitors of arachidonic acid, whose metabolites are involved in the inflammation process (Callegari and Zurier 1991; Gil 2002), and were demonstrated to decrease T cell proliferation (Rossetti et al. 1997). On the other hand, molecules derived from PUFAs could have positive effects on the treatment of MS: Lipoxins might reduce inflammation by decreasing neutrophil activity (Yacoubian and Serhan 2007), while resolvins and protectins, derived from omega-3 PUFAs, seem to control inflammation in the nervous system (Serhan et al. 2002). An important role assigned to PUFAs is that of ligands for peroxisome proliferator-activated receptors (PPARs). PPARs are ligandactivated nuclear transcription factors whose $\operatorname{PPAR}_{\gamma}$ isoform is present in human $\mathrm{T}$ lymphocytes, and omega-3 PUFAs, acting as $\mathrm{PPAR}_{\gamma}$ agonists, ameliorate inflammation in EAE rats (Niino et al. 2001). Furthermore, omega-3 PUFAs were demonstrated to promote, in vivo, the expression of myelin-related proteins such as the PLP and MBP (Salvati et al. 2008).

Considering the relevance of blood-brain barrier integrity in MS physiopathology, Liuzzi et al. (2007) demonstrated that the in vitro treatment of microglia with omega3 PUFAs decreases the LPS-induced production of matrix metalloproteinase-9, which is involved in the mechanism of blood-brain barrier disruption, the penetration of inflammatory cells into the CNS, and, consequently, demyelination.

Finally and most importantly, clinical trials have been conducted over the last few years in MS patients, with results supporting the positive role of dietary PUFAs in disease progression.

The fact that MS has low prevalence in equatorial regions and increasing prevalence toward the north and south poles and that sun exposure is inversely related to the risk for MS development (Munger et al. 2006) suggest that vitamin D3 (cholecalciferol) could have a significant influence on MS progression (Smolders et al. 2008a). Vitamin D can be obtained directly from dietary sources or through skin synthesis, in which case sunlight is essential to the conversion of pre-vitamin D3 to active vitamin D3 through the cleavage of the B-ring. Vitamin D is hydroxylated in the liver to render 25-hydroxyvitamin $D$ (25(OH)D). A high percentage of MS patients have low plasma levels of 25(OH)D (Mahon et al. 2003; Nieves et al. 1994; Ozgocmen et al. 2005). In this regard, studies in USA populations have proven that a 50 -nmol increase in $25(\mathrm{OH}) \mathrm{D}$ correlates with a $40 \%$ decrease in MS incidence. Also, while low levels of vitamin D are associated with relapse and disability in MS patients (Smolders et al. $2008 \mathrm{~b}$ ), high serum $25(\mathrm{OH}) \mathrm{D}$ levels reduce the hazard ratio for new relapses in a dose-dependent manner (Simpson et al. 2010). It has been proposed that the protective effects of vitamin D on MS are mostly related to the critical functions of this vitamin in the immune system. However, in the cuprizone model of demyelination in rats, which is independent of lymphocyte infiltration, vitamin D3 supplementation decreases the magnitude of white matter demyelination and mitigates the activation of microglia (Wergeland et al. 2011). In a more recent study, involving 141 participants with relapsing-remitting MS, Lin et al. studied 276 single nucleotide polymorphisms in 21 genes related to vitamin $\mathrm{D}$ metabolism and vitamin $\mathrm{D}$ receptor factor complex formation. They hypothesized that the interaction between genes and vitamin $\mathrm{D}$ may affect the clinical course of MS and, in particular, that the PKC family genes may be involved in the pathogenesis of relapsing-remitting $\mathrm{MS}$ modulating the association between 25(OH)D and relapse (Lin et al. 2013).

On the other hand, vitamin B12 cyanocobalamin can also have a positive influence on remyelination. B12 administered concomitantly with interferon- $\beta$ favors OL maturation both in vivo, in non-autoimmune primary demyelinating ND4 (DM20) transgenics, and in vitro, in the human MO313 cell line and in rat spinal cord oligodendrocytes. These actions involve a decrease in Notch1 signaling and an increase in the expression of Sonic hedgehog and its receptor, Patched, which induces OL maturation and helps improve remyelination (Mastronardi et al. 2004). 


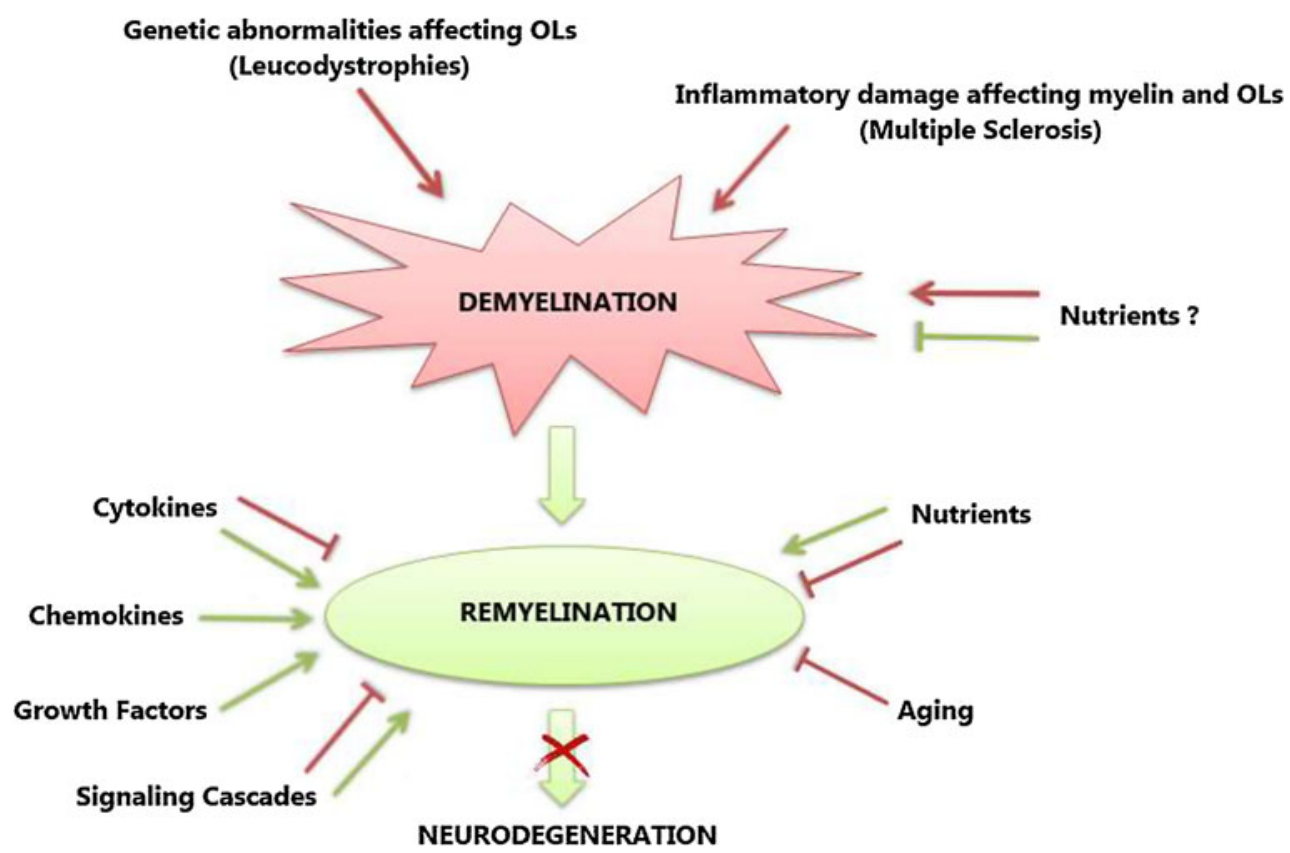

Fig. 1 Primary demyelination may be caused either by genetic abnormalities affecting OLs or by inflammatory damage affecting myelin and OLs, as is the case in MS. While some nutrients may play a protective role against demyelination (green line), others may play a negative role (red arrow). Remyelination is the physiological response to demyelination. During remyelination, some molecules act positively (green arrows) on the process, such as chemokines and

Dietary polyphenols could also mitigate demyelination by modulating the immune response. In this regard, epigallocatechin-3-gallate, a flavan-3-ol abundant in green tea, reduces the autoimmune response in the EAE through the inhibition of immune cell infiltration and the regulation of pro- and anti-autoimmune $\mathrm{CD} 4(+) \mathrm{T}$ cells (Wang et al. 2012).

In summary, recent experimental evidence suggests that nutrition could influence the development of demyelinating/remyelinating processes by mitigating demyelination and favoring remyelination. Given the nutritional imbalances associated with aging, further advances in the knowledge of how nutrients impact myelination could be of major relevance in the treatment of demyelinating conditions.

\section{Conclusions}

In demyelinating disorders in general and MS in particular, the failure of prompt remyelination is associated with axonal injury and degeneration, which is accepted as the major cause of neurological disability in the disease. Remyelination process recapitulates myelination during development, but in a pathological environment. Different molecules and signaling pathways are involved in the growth factors, while others may play a dual role (green arrows for positive, red lines for negative), such as certain signaling cascades and cytokines. Among environmental factors, nutrients may also play a dual role, and finally, aging has an unequivocally negative impact on the process. The interplay of these factors determines the fate of the remyelination process, whose failure leads to neurodegeneration

remyelination process, inducing or inhibiting the proliferation and maturation of OPCs engaged in the generation of new myelin sheaths around axons. In the same way, nondisease-related factors, such as age and genetic background, and environmental factors, such as dietary components, could act as predisposition factors or exert a protective or even therapeutic effect during certain disease stages, rendering either negative or positive outcomes (Fig. 1).

\section{References}

Adamo AM, Paez PM, Escobar Cabrera OE, Wolfson M, Franco PG, Pasquini JM, Soto EF (2006) Remyelination after cuprizoneinduced demyelination in the rat is stimulated by apotransferrin. Exp Neurol 198(2):519-529. doi:10.1016/j.expneurol.2005.12. 027

Agranoff BW, Goldberg D (1974) Diet and the geographical distribution of multiple sclerosis. Lancet 2(7888):1061-1066

Aguirre A, Dupree JL, Mangin JM, Gallo V (2007) A functional role for EGFR signaling in myelination and remyelination. Nat Neurosci 10(8):990-1002. doi:10.1038/nn1938

Antonovsky A, Leibowitz U, Smith HA, Medalie JM, Balogh M, Kats R, Halpern L, Alter M (1965) Epidemiologic study of multiple sclerosis in Israel. I. An overall review of methods and findings. Arch Neurol 13:183-193

Aparicio E, Mathieu P, Pereira Luppi M, Almeira Gubiani MF, Adamo AM (2013) The notch signaling pathway: its role in focal 
CNS demyelination and apotransferrin-induced remyelination. J Neurochem. doi:10.1111/jnc. 12440

Artavanis-Tsakonas S, Rand MD, Lake RJ (1999) Notch signaling: cell fate control and signal integration in development. Science 284(5415):770-776

Baker RW, Thompson RH, Zilkha KJ (1964) Serum fatty acids in multiple sclerosis. J Neurol Neurosurg Psychiatr 27:408-414

Beck J, Rondot P, Catinot L, Falcoff E, Kirchner H, Wietzerbin J (1988) Increased production of interferon gamma and tumor necrosis factor precedes clinical manifestation in multiple sclerosis: do cytokines trigger off exacerbations? Acta Neurol Scand 78(4):318-323

Berr C, Puel J, Clanet M, Ruidavets JB, Mas JL, Alperovitch A (1989) Risk factors in multiple sclerosis: a population-based case-control study in Hautes-Pyrenees France. Acta Neurol Scand 80(1):46-50

Blakemore WF, Keirstead HS (1999) The origin of remyelinating cells in the central nervous system. J Neuroimmunol 98(1):69-76

Callegari PE, Zurier RB (1991) Botanical lipids: potential role in modulation of immunologic responses and inflammatory reactions. Rheum Dis Clin North Am 17(2):415-425

Carroll WM, Jennings AR (1994) Early recruitment of oligodendrocyte precursors in CNS demyelination. Brain 117(Pt 3):563-578

Cendrowski W, Wender M, Dominik W, Flejsierowicz Z, Owsianowski M, Popiel M (1969) Epidemiological study of multiple sclerosis in western Poland. Eur Neurol 2(2):90-108

Cui XY, Hu QD, Tekaya M, Shimoda Y, Ang BT, Nie DY, Sun L, Hu WP, Karsak M, Duka T, Takeda Y, Ou LY, Dawe GS, Yu FG, Ahmed S, Jin LH, Schachner M, Watanabe K, Arsenijevic Y, Xiao ZC (2004) NB-3/Notch1 pathway via Deltex1 promotes neural progenitor cell differentiation into oligodendrocytes. J Biol Chem 279(24):25858-25865. doi:10.1074/jbc. M313505200

de Jong BA, Huizinga TW, Bollen EL, Uitdehaag BM, Bosma GP, van Buchem MA, Remarque EJ, Burgmans AC, Kalkers NF, Polman CH, Westendorp RG (2002) Production of IL-1beta and IL-1Ra as risk factors for susceptibility and progression of relapse-onset multiple sclerosis. J Neuroimmunol 126(1-2):172-179

Ebers GC, Sadovnick AD (1994) The role of genetic factors in multiple sclerosis susceptibility. J Neuroimmunol 54(1-2):1-17

Escobar Cabrera OE, Bongarzone ER, Soto EF, Pasquini JM (1994) Single intracerebral injection of apotransferrin in young rats induces increased myelination. Dev Neurosci 16(5-6):248-254

Escobar Cabrera OE, Zakin MM, Soto EF, Pasquini JM (1997) Single intracranial injection of apotransferrin in young rats increases the expression of specific myelin protein mRNA. J Neurosci Res 47(6):603-608

Escobar Cabrera OE, Soto EF, Pasquini JM (2000) Myelin membranes isolated from rats intracranially injected with apotransferrin are more susceptible to in vitro peroxidation. Neurochem Res 25(1):87-93

Espinosa de los Monteros A, Pena LA, de Vellis J (1989) Does transferrin have a special role in the nervous system? J Neurosci Res 24(2):125-136. doi:10.1002/jnr.490240202

Espinosa de los Monteros A, Kumar S, Zhao P, Huang CJ, Nazarian R, Pan T, Scully S, Chang R, de Vellis J (1999) Transferrin is an essential factor for myelination. Neurochem Res 24(2):235-248

Espinosa-Jeffrey A, Kumar S, Zhao PM, Awosika O, Agbo C, Huang A, Chang R, De Vellis J (2002) Transferrin regulates transcription of the MBP gene and its action synergizes with IGF-1 to enhance myelinogenesis in the md rat. Dev Neurosci 24(2-3):227-241

Fancy SP, Baranzini SE, Zhao C, Yuk DI, Irvine KA, Kaing S, Sanai N, Franklin RJ, Rowitch DH (2009) Dysregulation of the Wnt pathway inhibits timely myelination and remyelination in the mammalian CNS. Genes Dev 23(13):1571-1585. doi:10.1101/ gad.1806309

Ferent J, Zimmer C, Durbec P, Ruat M, Traiffort E (2013) Sonic Hedgehog signaling is a positive oligodendrocyte regulator during demyelination. J Neurosci 33(5):1759-1772. doi:10.1523/ JNEUROSCI.3334-12.2013

Franklin RJ (2002) Why does remyelination fail in multiple sclerosis? Nat Rev Neurosci 3(9):705-714. doi:10.1038/nrn917

Franklin RJ, Ffrench-Constant C (2008) Remyelination in the CNS: from biology to therapy. Nat Rev Neurosci 9(11):839-855. doi: $10.1038 / \mathrm{nrn} 2480$

Fuccillo M, Joyner AL, Fishell G (2006) Morphogen to mitogen: the multiple roles of hedgehog signalling in vertebrate neural development. Nat Rev Neurosci 7(10):772-783. doi:10.1038/ nrn1990

Gil A (2002) Polyunsaturated fatty acids and inflammatory diseases. Biomed Pharmacother 56(8):388-396

Gul S, Smith AD, Thompson RH, Wright HP, Zilkha KJ (1970) Fatty acid composition of phospholipids from platelets and erythrocytes in multiple sclerosis. J Neurol Neurosurg Psychiatr 33(4):506-510

Harbige LS, Layward L, Morris-Downes MM, Dumonde DC, Amor S (2000) The protective effects of omega- 6 fatty acids in experimental autoimmune encephalomyelitis (EAE) in relation to transforming growth factor-beta 1 (TGF-beta1) up-regulation and increased prostaglandin E2 (PGE2) production. Clin Exp Immunol 122(3):445-452

Hinks GL, Franklin RJ (2000) Delayed changes in growth factor gene expression during slow remyelination in the CNS of aged rats. Mol Cell Neurosci 16(5):542-556. doi:10.1006/mcne.2000.0897

Hu QD, Ang BT, Karsak M, Hu WP, Cui XY, Duka T, Takeda Y, Chia W, Sankar N, Ng YK, Ling EA, Maciag T, Small D, Trifonova R, Kopan R, Okano H, Nakafuku M, Chiba S, Hirai H, Aster JC, Schachner M, Pallen CJ, Watanabe K, Xiao ZC (2003) F3/contactin acts as a functional ligand for Notch during oligodendrocyte maturation. Cell 115(2):163-175

Isaacs EB, Fischl BR, Quinn BT, Chong WK, Gadian DG, Lucas A (2010) Impact of breast milk on intelligence quotient, brain size, and white matter development. Pediatr Res 67(4):357-362. doi:10.1203/PDR.0b013e3181d026da

John GR, Shankar SL, Shafit-Zagardo B, Massimi A, Lee SC, Raine CS, Brosnan CF (2002) Multiple sclerosis: re-expression of a developmental pathway that restricts oligodendrocyte maturation. Nat Med 8(10):1115-1121. doi:10.1038/nm781

Junker A, Krumbholz M, Eisele S, Mohan H, Augstein F, Bittner R, Lassmann H, Wekerle H, Hohlfeld R, Meinl E (2009) MicroRNA profiling of multiple sclerosis lesions identifies modulators of the regulatory protein CD47. Brain 132(Pt 12):3342-3352. doi:10.1093/brain/awp300

Keirstead HS, Blakemore WF (1997) Identification of post-mitotic oligodendrocytes incapable of remyelination within the demyelinated adult spinal cord. J Neuropathol Exp Neurol 56(11):1191-1201

Kopan R, Ilagan MX (2009) The canonical Notch signaling pathway: unfolding the activation mechanism. Cell 137(2):216-233. doi:10.1016/j.cell.2009.03.045

Kotter MR, Li WW, Zhao C, Franklin RJ (2006) Myelin impairs CNS remyelination by inhibiting oligodendrocyte precursor cell differentiation. J Neurosci 26(1):328-332. doi:10.1523/JNEUR OSCI.2615-05.2006

Lewis J (1996) Neurogenic genes and vertebrate neurogenesis. Curr Opin Neurobiol 6(1):3-10

Lin R, Taylor BV, Simpson S Jr, Charlesworth J, Ponsonby AL, Pittas F, Dwyer T, van der Mei IA (2013) Novel modulating effects of PKC family genes on the relationship between serum vitamin D 
and relapse in multiple sclerosis. J Neurol Neurosurg Psychiatr. doi:10.1136/jnnp-2013-305245

Liuzzi GM, Latronico T, Rossano R, Viggiani S, Fasano A, Riccio P (2007) Inhibitory effect of polyunsaturated fatty acids on MMP9 release from microglial cells-implications for complementary multiple sclerosis treatment. Neurochem Res 32(12):2184-2193. doi:10.1007/s11064-007-9415-9

Loulier K, Ruat M, Traiffort E (2006) Increase of proliferating oligodendroglial progenitors in the adult mouse brain upon Sonic hedgehog delivery in the lateral ventricle. J Neurochem 98(2):530-542. doi:10.1111/j.1471-4159.2006.03896.x

Mahon BD, Gordon SA, Cruz J, Cosman F, Cantorna MT (2003) Cytokine profile in patients with multiple sclerosis following vitamin D supplementation. J Neuroimmunol 134(1-2):128-132

Maimone D, Gregory S, Arnason BG, Reder AT (1991) Cytokine levels in the cerebrospinal fluid and serum of patients with multiple sclerosis. J Neuroimmunol 32(1):67-74

Mason JL, Suzuki K, Chaplin DD, Matsushima GK (2001) Interleukin-1beta promotes repair of the CNS. J Neurosci 21(18):7046-7052

Mastronardi FG, Min W, Wang H, Winer S, Dosch M, Boggs JM, Moscarello MA (2004) Attenuation of experimental autoimmune encephalomyelitis and nonimmune demyelination by IFN-beta plus vitamin B12: treatment to modify notch-1/sonic hedgehog balance. J Immunol 172(10):6418-6426

Meade CJ, Mertin J, Sheena J, Hunt R (1978) Reduction by linoleic acid of the severity of experimental allergic encephalomyelitis in the guinea pig. J Neurol Sci 35(2-3):291-308

Menn B, Garcia-Verdugo JM, Yaschine C, Gonzalez-Perez O, Rowitch D, Alvarez-Buylla A (2006) Origin of oligodendrocytes in the subventricular zone of the adult brain. J Neurosci 26(30):7907-7918. doi:10.1523/JNEUROSCI.1299-06.2006

Mi S, Miller RH, Lee X, Scott ML, Shulag-Morskaya S, Shao Z, Chang J, Thill G, Levesque M, Zhang M, Hession C, Sah D, Trapp B, He Z, Jung V, McCoy JM, Pepinsky RB (2005) LINGO-1 negatively regulates myelination by oligodendrocytes. Nat Neurosci 8(6):745-751. doi:10.1038/nn1460

Mi S, Hu B, Hahm K, Luo Y, Kam Hui ES, Yuan Q, Wong WM, Wang L, Su H, Chu TH, Guo J, Zhang W, So KF, Pepinsky B, Shao Z, Graff C, Garber E, Jung V, Wu EX, Wu W (2007) LINGO-1 antagonist promotes spinal cord remyelination and axonal integrity in MOG-induced experimental autoimmune encephalomyelitis. Nat Med 13(10):1228-1233. doi:10.1038/ $\mathrm{nm} 1664$

Mi S, Miller RH, Tang W, Lee X, Hu B, Wu W, Zhang Y, Shields CB, Miklasz S, Shea D, Mason J, Franklin RJ, Ji B, Shao Z, Chedotal A, Bernard F, Roulois A, Xu J, Jung V, Pepinsky B (2009) Promotion of central nervous system remyelination by induced differentiation of oligodendrocyte precursor cells. Ann Neurol 65(3):304-315. doi:10.1002/ana.21581

Munger KL, Levin LI, Hollis BW, Howard NS, Ascherio A (2006) Serum 25-hydroxyvitamin D levels and risk of multiple sclerosis. JAMA 296(23):2832-2838. doi:10.1001/jama.296.23.2832

Murtie JC, Zhou YX, Le TQ, Vana AC, Armstrong RC (2005) PDGF and FGF2 pathways regulate distinct oligodendrocyte lineage responses in experimental demyelination with spontaneous remyelination. Neurobiol Dis 19(1-2):171-182. doi:10.1016/j. nbd.2004.12.006

Neu IS (1983) Essential fatty acids in the serum and cerebrospinal fluid of multiple sclerosis patients. Acta Neurol Scand 67(3):151-163

Nieves J, Cosman F, Herbert J, Shen V, Lindsay R (1994) High prevalence of vitamin $\mathrm{D}$ deficiency and reduced bone mass in multiple sclerosis. Neurology 44(9):1687-1692

Niino M, Iwabuchi K, Kikuchi S, Ato M, Morohashi T, Ogata A, Tashiro K, Onoe K (2001) Amelioration of experimental autoimmune encephalomyelitis in C57BL/6 mice by an agonist of peroxisome proliferator-activated receptor-gamma. J Neuroimmunol 116(1):40-48

Ozgocmen S, Bulut S, Ilhan N, Gulkesen A, Ardicoglu O, Ozkan Y (2005) Vitamin D deficiency and reduced bone mineral density in multiple sclerosis: effect of ambulatory status and functional capacity. J Bone Miner Metab 23(4):309-313. doi:10.1007/ s00774-005-0604-9

Patel JR, McCandless EE, Dorsey D, Klein RS (2010) CXCR4 promotes differentiation of oligodendrocyte progenitors and remyelination. Proc Natl Acad Sci USA 107(24):11062-11067. doi:10.1073/pnas.1006301107

Payne A (2001) Nutrition and diet in the clinical management of multiple sclerosis. J Hum Nutr Diet 14(5):349-357

Prayoonwiwat N, Rodriguez M (1993) The potential for oligodendrocyte proliferation during demyelinating disease. J Neuropathol Exp Neurol 52(1):55-63

Qi Y, Cai J, Wu Y, Wu R, Lee J, Fu H, Rao M, Sussel L, Rubenstein J, Qiu M (2001) Control of oligodendrocyte differentiation by the Nkx2.2 homeodomain transcription factor. Development 128(14):2723-2733

Redmond SA, Chan JR (2012) Neuroscience. Revitalizing remyelination-the answer is circulating. Science 336(6078):161-162. doi:10.1126/science.1221689

Rosenbluth J (1999) A brief history of myelinated nerve fibers: one hundred and fifty years of controversy. J Neurocytol 28(4-5):251-262

Rossetti RG, Seiler CM, DeLuca P, Laposata M, Zurier RB (1997) Oral administration of unsaturated fatty acids: effects on human peripheral blood $\mathrm{T}$ lymphocyte proliferation. J Leukoc Biol 62(4):438-443

Ruckh JM, Zhao JW, Shadrach JL, van Wijngaarden P, Rao TN, Wagers AJ, Franklin RJ (2012) Rejuvenation of regeneration in the aging central nervous system. Cell Stem Cell 10(1):96-103. doi:10.1016/j.stem.2011.11.019

Salvati S, Natali F, Attorri L, Di Benedetto R, Leonardi F, Di Biase A, Ferri F, Fortuna S, Lorenzini P, Sanchez M, Ricceri L, Vitelli L (2008) Eicosapentaenoic acid stimulates the expression of myelin proteins in rat brain. J Neurosci Res 86(4):776-784. doi:10.1002/jnr.21537

Sanders H, Thompson RH, Wright HP, Zilkha KJ (1968) Further studies on platelet adhesiveness and serum cholesteryl linoleate levels in multiple sclerosis. J Neurol Neurosurg Psychiatr 31(4):321-325

Sepcic J, Mesaros E, Materljan E, Sepic-Grahovac D (1993) Nutritional factors and multiple sclerosis in Gorski Kotar Croatia. Neuroepidemiology 12(4):234-240

Serhan CN, Hong S, Gronert K, Colgan SP, Devchand PR, Mirick G, Moussignac RL (2002) Resolvins: a family of bioactive products of omega- 3 fatty acid transformation circuits initiated by aspirin treatment that counter proinflammation signals. J Exp Med 196(8):1025-1037

Shen S, Sandoval J, Swiss VA, Li J, Dupree J, Franklin RJ, CasacciaBonnefil P (2008) Age-dependent epigenetic control of differentiation inhibitors is critical for remyelination efficiency. Nat Neurosci 11(9):1024-1034. doi:10.1038/nn.2172

Shields SA, Gilson JM, Blakemore WF, Franklin RJ (1999) Remyelination occurs as extensively but more slowly in old rats compared to young rats following gliotoxin-induced CNS demyelination. Glia 28(1):77-83

Sim FJ, Zhao C, Penderis J, Franklin RJ (2002) The age-related decrease in CNS remyelination efficiency is attributable to an impairment of both oligodendrocyte progenitor recruitment and differentiation. J Neurosci 22(7):2451-2459. doi:20026217

Simpson S Jr, Taylor B, Blizzard L, Ponsonby AL, Pittas F, Tremlett H, Dwyer T, Gies P, van der Mei I (2010) Higher 
25-hydroxyvitamin $\mathrm{D}$ is associated with lower relapse risk in multiple sclerosis. Ann Neurol 68(2):193-203. doi:10.1002/ana. 22043

Smolders J, Damoiseaux J, Menheere P, Hupperts R (2008a) Vitamin $\mathrm{D}$ as an immune modulator in multiple sclerosis, a review. J Neuroimmunol 194(1-2):7-17. doi:10.1016/j.jneuroim.2007. 11.014

Smolders J, Menheere P, Kessels A, Damoiseaux J, Hupperts R (2008b) Association of vitamin D metabolite levels with relapse rate and disability in multiple sclerosis. Mult Scler 14(9):1220-1224. doi:10.1177/1352458508094399

Stumm R, Kolodziej A, Schulz S, Kohtz JD, Hollt V (2007) Patterns of SDF-1alpha and SDF-1gamma mRNAs, migration pathways, and phenotypes of CXCR4-expressing neurons in the developing rat telencephalon. J Comp Neurol 502(3):382-399. doi:10.1002/ cne. 21336

Tola MR, Granieri E, Malagu S, Caniatti L, Casetta I, Govoni V, Paolino E, Cinzia Monetti V, Canducci E, Panatta GB (1994) Dietary habits and multiple sclerosis. A retrospective study in Ferrara Italy. Acta Neurologica 16(4):189-197

Trapp BD, Nave KA (2008) Multiple sclerosis: an immune or neurodegenerative disorder? Annu Rev Neurosci 31:247-269. doi:10.1146/annurev.neuro.30.051606.094313

Tsai HH, Frost E, To V, Robinson S, Ffrench-Constant C, Geertman R, Ransohoff RM, Miller RH (2002) The chemokine receptor CXCR2 controls positioning of oligodendrocyte precursors in developing spinal cord by arresting their migration. Cell 110(3):373-383

Villeda SA, Luo J, Mosher KI, Zou B, Britschgi M, Bieri G, Stan TM, Fainberg N, Ding Z, Eggel A, Lucin KM, Czirr E, Park JS, Couillard-Despres S, Aigner L, Li G, Peskind ER, Kaye JA, Quinn JF, Galasko DR, Xie XS, Rando TA, Wyss-Coray T (2011) The ageing systemic milieu negatively regulates neurogenesis and cognitive function. Nature 477(7362):90-94. doi:10. 1038/nature 10357

Wang S, Sdrulla AD, diSibio G, Bush G, Nofziger D, Hicks C, Weinmaster G, Barres BA (1998) Notch receptor activation inhibits oligodendrocyte differentiation. Neuron 21(1):63-75
Wang J, Ren Z, Xu Y, Xiao S, Meydani SN, Wu D (2012) Epigallocatechin-3-gallate ameliorates experimental autoimmune encephalomyelitis by altering balance among CD4 $+\mathrm{T}$ cell subsets. Am J Pathol 180(1):221-234. doi:10.1016/j.ajpath. 2011.09.007

Waxman SG (2006) Axonal conduction and injury in multiple sclerosis: the role of sodium channels. Nat Rev Neurosci 7(12):932-941. doi:10.1038/nrn2023

Wergeland S, Torkildsen O, Myhr KM, Aksnes L, Mork SJ, Bo L (2011) Dietary vitamin D3 supplements reduce demyelination in the cuprizone model. PLoS ONE 6(10):e26262. doi:10.1371/ journal.pone.0026262

Wilson HC, Scolding NJ, Raine CS (2006) Co-expression of PDGF alpha receptor and NG2 by oligodendrocyte precursors in human CNS and multiple sclerosis lesions. J Neuroimmunol 176(1-2):162-173. doi:10.1016/j.jneuroim.2006.04.014

Wood PM, Bunge RP (1991) The origin of remyelinating cells in the adult central nervous system: the role of the mature oligodendrocyte. Glia 4(2):225-232. doi:10.1002/glia.440040214

Yacoubian S, Serhan CN (2007) New endogenous anti-inflammatory and proresolving lipid mediators: implications for rheumatic diseases. Nat Clin Pract Rheumatol 3(10):570-579. doi:10.1038/ ncprheum0616

Ye F, Chen Y, Hoang T, Montgomery RL, Zhao XH, Bu H, Hu T, Taketo MM, van Es JH, Clevers H, Hsieh J, Bassel-Duby R, Olson EN, Lu QR (2009) HDAC1 and HDAC2 regulate oligodendrocyte differentiation by disrupting the beta-cateninTCF interaction. Nat Neurosci 12(7):829-838. doi:10.1038/nn. 2333

Zhao C, Li WW, Franklin RJ (2006) Differences in the early inflammatory responses to toxin-induced demyelination are associated with the age-related decline in CNS remyelination. Neurobiol Aging 27(9):1298-1307. doi:10.1016/j.neurobiola ging.2005.06.008 